\title{
BMJ Open Medical school predictors of later perceived mastery of clinical work among Norwegian doctors: a cohort study with 10-year and 20-year follow-
} up

\author{
Anna Belfrage, ${ }^{1,2}$ Kjersti Støen Grotmol, ${ }^{1,3}$ Lars Lien, ${ }^{2}$ Torbjørn Moum, ${ }^{1}$ \\ Ragna Veslemøy Wiese, ${ }^{1}$ Reidar Tyssen ${ }^{1}$
}

To cite: Belfrage A, Grotmol KS, Lien L, et al. Medical school predictors of later perceived mastery of clinical work among Norwegian doctors: a cohort study with 10-year and 20year follow-up. BMJ Open 2017;7:e014462. doi:10.1136/ bmjopen-2016-014462

- Prepublication history for this paper is available online. To view these files please visit the journal online (http://dx.doi. org/10.1136/bmjopen-2016014462).

Received 28 September 2016 Accepted 1 August 2017

CrossMark

${ }^{1}$ Department of Behavioural Sciences in Medicine, Institute of Basic Medical Sciences, Faculty of Medicine, University of Oslo, Oslo, Norway

${ }^{2}$ Norwegian National Advisory Unit on Concurrent Substance Abuse and Mental Health Disorders, Innlandet Hospital Trust, Brumunddal, Norway ${ }^{3}$ Department of Oncology, Regional Centre of Excellence in Palliative Care, Oslo University Hospital, Oslo, Norway

Correspondence to

Anna Belfrage;

anna.belfrage@medisin.uio.no

\section{ABSTRACT}

Objective Doctors' self-perceived mastery of clinical work might have an impact on their career and patient care, in addition to their own health and well-being. The aim of this study is to identify predictors at medical school of perceived mastery later in doctors' careers.

Design A cohort of medical students $(n=631)$ was surveyed in the final year of medical school in 1993/1994 (T1), and 10 (T2) and 20 (T3) years later.

Setting Nationwide healthcare institutions.

Participants Medical students from all universities in Norway.

Main outcome measures Perceived mastery of clinical work was measured at T2 and T3. The studied predictors measured at $\mathrm{T} 1$ included personality traits, medical school stress, perceived medical recording skills, identification with the role of doctor, hazardous drinking and drinking to cope, in addition to age and gender. Effects were studied using multiple linear regression models.

Results Response rates: T1, 522/631 (83\%); T2, 390/522 (75\%); and T3, 303/522 (58\%). Mean scores at T2 and T3 were 22.3 ( $\mathrm{SD}=4.2)$ and 24.5 (3.0) $(\mathrm{t}=8.2, \mathrm{p}<0.001)$, with no gender difference. Adjusted associations at T2 were: role identification $(\beta=0.16 ; p=0.006 ; 95 \% \mathrm{Cl} 0.05$ to $0.28)$, perceived medical recording skills ( $\beta=0.13$; $p=0.02$; $95 \% \mathrm{Cl} 0.02$ to 0.24$)$ and drinking to cope ( $\beta=-2.45$; $\mathrm{p}=0.001 ; 95 \% \mathrm{Cl}-3.88$ to -1.03$)$. Adjusted association at T3 was perceived medical recording skills $(\beta=0.11$; $\mathrm{p}=0.015 ; 95 \% \mathrm{Cl} 0.02$ to 0.21 ).

Conclusions Perceived medical recording skills and role identification were associated with higher perceived mastery. Medical schools should provide experiences, teaching and assessment to enhance students' physician role identification and confidence in their own skills. Drinking to cope was associated with lower perceived mastery, which indicates the importance of acquiring healthier coping strategies in medical school.

\section{INTRODUCTION}

Physicians are often exposed to high levels of stress, a risk factor for developing psychological disorders ${ }^{12}$ that might influence their
Strengths and limitations of this study

- This study has a 20-year prospective design, a nationwide sample and a relatively high response rate.

- This is the first prospective study of potentially modifiable factors at medical school that may impact on doctors' future perceived mastery of work.

- The data are based on self-report and could be biased, though the predictor model has been controlled for personality traits.

- We have not controlled for contextual variables such as specialty and position that may have influenced the results.

work performance and patient care. ${ }^{34}$ A sense of mastering a stressful situation is believed to reduce negative stress and could be a protective factor against disorders of psychological origin. ${ }^{5-7}$ Still, the perception of mastery of work has been scarcely studied in occupational psychology in general, ${ }^{8}$ and we lack studies on long-term predictors of perceived mastery of work among medical doctors. Such findings could help inform medical schools about curriculum factors that are important for students' future work as doctors.

Self-perceived mastery is similar to self-efficacy: the difference being that mastery refers to the perception of having handled a specific situation in a preferable way, while self-efficacy refers to the perception of having the abilities to handle that type of situations in the future. ${ }^{8}$ Bandura used the term 'mastery experiences' as preceding self-efficacy. ${ }^{9}$ That is, we need to have experiences of mastery to be able to feel self-efficacy.

A high sense of mastery makes it easier to handle high professional demands. ${ }^{10}$ To attain a sense of mastery, it is however 
essential to have had some initial experiences of stressful demands. Moreover, the stressful or demanding situation needs to be handled with a sense of control. This combination of high demands and high control is proposed to lead to increased learning, which in turn is believed to enhance perceived mastery. ${ }^{12}{ }^{12}$ It is in this respect important that the student or doctor acknowledges that handling the situation in a successful manner was due to actions carried out by himself/herself. Therefore, since being in medical school is demanding, ${ }^{13}$ we believe that both exposure to curriculum stress and learning clinical skills might be important factors in the development of mastery. Communication skills courses among medical students have been shown to increase their future communication skills self-efficacy and to enhance their objectively observed performance. ${ }^{14}$ One could argue that both biomedical knowledge and communication skills are called for when taking a medical history and writing up a medical record. Confidence in these skills have also been found to predict lower job stress during internship. ${ }^{15}$

In addition to communication skills, role identification might be important for the development of professional clinical competence. ${ }^{16}{ }^{17}$ In occupational psychology, role conflict has been associated with higher tension and anxiety, lower work participation and lack of confidence. ${ }^{18}$ Therefore, we aimed to investigate whether strong identification with the role of being a doctor in the final year of medical school ${ }^{19}$ would promote perceived mastery later in a doctor's career. Personality may also be of importance, in particular dimensions such as vulnerability (or neuroticism) and extraversion. Associations have been found between neuroticism and lower perceived mastery of work. ${ }^{20}$ An association between personality and job stress has also been shown, where vulnerability predicts higher stress and extraversion predicts lower stress. ${ }^{21}$

Alcohol can be used to cope with a stressful situation, also among medical students and physicians. ${ }^{22-24}$ Therefore, we hypothesise that early problematic drinking behaviour, which is linked to later hazardous drinking, ${ }^{24}$ might have an impact on later perceived mastery.

The purpose of this study was to explore predictors in the final year of medical school of perceived mastery of clinical work (PMCW) 10 and 20 years after leaving medical school. We hypothesise that the personality trait of vulnerability and problematic alcohol habits measured in medical school are associated with relatively low perceived mastery later in the career, while students' confidence in their own medical recording skills and high identification with the role of doctor are hypothesised to predict higher perceived mastery. After 20 years of work experience, doctors are in more established, senior and leading positions than they were 10 years earlier. Therefore, we were interested in finding out whether there would be different predictors of mastery of work at these two stages. We also aimed to study any gender differences in our studied predictors.

\section{METHODS}

\section{Participants and study design}

This was a prospective study of the Young Doctor Cohort ( $n=631)$ of the Longitudinal Study of Norwegian Medical Students and Doctors (NORDOC). ${ }^{2} 15192324$ The cohort sample consisted of twoyear classes (1993/1994) from all four medical schools in Norway, who were surveyed with postal questionnaires at three time points. In the final year of medical school in 1993/1994 (T1), 522/631 (83\%) responded; 390/522 $(75 \%)$ responded 10 years after graduation in 2003 (T2) and 303/522 (58\%) responded 20 years after graduation in 2014 (T3). Responders of all items measuring PMCW were $371 / 522(71 \%)$ at T2 and $289 / 522(55 \%)$ at T3.

\section{Measures}

Using a pool of 10 items relating to clinical competence and communication, a factor analysis was performed, revealing three rather distinct dimensions or factors, one of which had high $(>0.6)$ loadings from a subset of four items relating to PMCW (rotated eigenvalue $=2.54$ ). This subset proved to be highly scalable (Cronbach's $\alpha=0.88$ at T2 and 0.84 at T3), yielding a simple additive index (PMCW) which, in substantive terms, is rather similar to the Perceived Mastery of Work four-item scale of the General Nordic Questionnaire for psychological and social factors at work ${ }^{8}$ but is more specifically related to clinical work. PMCW was measured at T2 and T3. The four items measuring PMCW were: 'I have sufficient knowledge and experience to do a good job as a physician', 'I communicate without problems with patients and their next-of-kin', 'I manage to establish collaboration with patients who are poor collaborators to begin with' and 'I experience that I master the professional aspects that my work demands of me'. Responses were on a 7-point Likert scale from $1=$ 'I agree' to $7=$ =I don't agree'. The PMCW scores ranged from 4 to 28 , and the scale was measured continuously.

\section{Predictor variables}

The predictor variables are listed in table 1. Because multicollinearity tests indicated high internal correlations between the previously validated variables, perceived diagnostic skills and perceived medical recording skills, ${ }^{25}$ we excluded the former variable in the final model.

Personality traits were measured by the Basic Character Inventory, originally constructed by Lazare et $a l^{26}$ and modified by Torgersen. ${ }^{27} 28$ The 36 -item version has been used and validated in several former NORDOC-based studies. ${ }^{15} 19212425$ To limit the size of the comprehensive questionnaires (30 pages), it was measured at $\mathrm{T} 1$ for half of the sample and 1 year later for the other half. It consists of four personality dimensions: (1) vulnerability (measuring emotionally weakness/dependency/insecurity/'neuroticism'); (2) intensity (extraversion/affectivity/ impulsiveness); (3) control (obsessiveness/rigidity); and (4) reality weakness (overwhelming perceptions of the world/thoughts on the borderline between reality and 


\begin{tabular}{|c|c|c|}
\hline Predictor variables & $\begin{array}{l}\text { Mean (SD) } \\
\text { or } \%\end{array}$ & Range \\
\hline \multicolumn{3}{|l|}{ Demographic factors } \\
\hline Age & $28(2.8)$ & $24-49$ \\
\hline Women & 57 & \\
\hline \multicolumn{3}{|l|}{ Personality } \\
\hline Vulnerability* & $3.5(2.3)$ & $0-9$ \\
\hline Control & $3.1(2.0)$ & $0-9$ \\
\hline Intensity & $5.6(2.5)$ & $0-9$ \\
\hline Reality weakness & $1.1(1.4)$ & $0-8$ \\
\hline \multicolumn{3}{|l|}{ Medical school factors } \\
\hline Perceived medical school stress & $20.4(6.8)$ & $3-40$ \\
\hline Identification with the role of doctor & $18.8(4.4)$ & $4-28$ \\
\hline Perceived medical recording skills & $28.6(4.8)$ & $15-42$ \\
\hline \multicolumn{3}{|l|}{ Alcohol drinking habits } \\
\hline Hazardous drinking $\ddagger$ & 11 & \\
\hline Use of alcohol to cope with tension & 11 & \\
\hline
\end{tabular}

*Significant gender difference $(t=5.01, p<0.001)$ : women: 3.9 , $\mathrm{SD}=2.2 /$ men: $2.9, \mathrm{SD}=2.2$.

†Significant gender difference $(\mathrm{t}=-2.35, \mathrm{p}=0.02)$ : women: 18.4 , $\mathrm{SD}=4.3 /$ men: $19.3, \mathrm{SD}=4.4$.

łSignificant gender difference $(\mathrm{t}=6.13, \mathrm{p}<0.001)$ : women: $4.7 \% /$ men: $21.9 \%$.

fantasy). ${ }^{28}$ Each dimension is based on nine items, with a dichotomous response (agree/do not agree), giving a score range between 0 (low) and 9 (high). Each dimension was used as a continuous measure. Cronbach's $\alpha$ : vulnerability $=0.76$, intensity $=0.77$, control $=0.63$ and reality weakness $=0.62 .{ }^{25}$

Perceived medical school stress (PMSS) was measured by a 13-item questionnaire designed to measure stress derived from medical school-related situations, originally developed by Vitaliano et $a t^{29}$ and slightly modified to suit Norwegian students. ${ }^{30}$ The instrument has been validated in several previous studies. ${ }^{31-33}$ Responses were on a 5-point Likert scale, ranging from 1='strongly disagree' to $5=$ 'strongly agree' (coded as $0-4$ in the final analyses), giving a scale range between 0 and 52 . This variable was measured continuously. Cronbach's $\alpha=0.77 .^{30}$

Perceived medical recording skills were measured by a previously validated instrument ${ }^{152531}$ of six items covering skills in taking a medical history and writing up relevant information from an interview with the patient: 'It is difficult/easy to get a summary when the patient's medical history is extensive', 'It is difficult/easy to formulate the present illness in the medical records', 'I manage to direct the interview so that I get the relevant information about the medical history', 'I easily get an overview of the progress of the present illness', 'I manage to get the necessary information about the present illness' and 'I am sure about how to describe my findings from the physical examination'. Responses were on a 7-point Likert scale where $1=$ difficult/uncertain/never and $7=$ easy/certain/ always, giving a scale range between 6 and 42. This variable was measured continuously. Cronbach's $\alpha=0.77$.

Identification with the role of doctor was measured using four items, described and validated elsewhere ${ }^{19}:^{\text {'I }}$ feel like a doctor in the emergency room', 'I feel that I do genuine doctor's work in the emergency room', 'I generally feel like a doctor' and 'I like being treated as a doctor'. Responses were on a 7-point Likert scale where $1=$ never/little and $7=$ =always/very much, giving a scale range between 4 and 28. This variable was measured continuously. Cronbach's $\alpha=0.77$.

Hazardous drinking was measured by one question and defined as drinking $60 \mathrm{~g}$ of ethanol (approximately 5 alcoholic units) on the same occasion at least 2-3 times per month. ${ }^{2324}$ This variable was dichotomised as $1=2-3$ times per month or more frequently, and $0=1$ time per month or less frequently.

Drinking to cope with tension was measured with the question "when you feel worried, tense, or nervous, do you ever drink alcoholic beverages to help you handle things?', which has been validated previously. ${ }^{2324} 34$ The variable was dichotomised as $1=$ seldom, now-and-then or often, and $0=$ never.

\section{Statistical analyses}

We used the Statistical Package for the Social Sciences (SPSS) V.22.0. The internal consistency (or reliability) of PMCW was measured by Cronbach's $\alpha$. Difference between T2 and T3 was tested by paired sample t-test; effect sizes are measured by Cohen's $d$.

The PMCW scores were fairly normally distributed at $\mathrm{T} 2$ and T3 and frequencies of maximum score were $5 \%$ at $\mathrm{T} 2 \%$ and $13 \%$ at T3. The mean values were very close to the $5 \%$ trimmed mean values (22.66 vs 22.32 at T2 and 24.84 vs 24.55 at T3), which indicates that the risk of ceiling/floor effects was small. We therefore used linear regression analysis to study the effects of independents. Initially, we studied univariate regressions on PMCW at T2 and T3, respectively. Effects were measured by standardised and unstandardised regression coefficients. Second, all independents were controlled for each other (adjusted) in four different blocks in a stepwise multiple regression model of PMCW at both periods. With respect to when the variables most probably occurred in time, the blocks were put into the model as follows: block 1: demographics; block 2: personality; block 3: alcohol drinking behaviour; and block 4: medical school factors. The explained variance of PMCW was indicated by adjusted $R^{2}$. Change in adjusted $R^{2}$ is also presented for each of the different blocks. Kolmogorov-Smirnov and Shapiro-Wilk tests of normality were however both significant (T2: Kolmogorov-Smirnov: 0.17, p<0.001, Shapiro-Wilk: 0.89, $\mathrm{p}<0.001$, T3: Kolmogorov-Smirnov: 0.13, $\mathrm{p}<0.001$, Shapiro-Wilk: $0.85, \mathrm{p}<0.001$ ), which means that the scores fit the normal curve poorly. This is quite common in large samples; nevertheless, we performed additional analyses with logistic regression models (with PMCW dichotomised 
by median) to rule out the risk of misleading associations due to potential ceiling/floor effects. In additional analyses we controlled for adjusted effects of PMCW scores of T2 on T3, by including PMCW at T2 in the regression model predicting PMCW at T3.

We tested for statistical interactions between gender and all predictors, using analysis of covariance (ANCOVA) with one interaction term enter at a time to reveal differential effects by gender for any of the predictors. Statistical significance was set at $\mathrm{p}<0.05$.

Post hoc, we checked heteroscedasticity (using Breusch-Pagan test), curvilinearity (using ANCOVAs) and tests to rule out potentially influential outliers (using casewise diagnostics in combination with Cook's distance test).

\section{Missing data}

Included in the analyses were respondents of all four items measuring the PMCW variable, as well as responders of all items of all predictor variables, except for the four personality dimensions that were sent to half of the sample at $\mathrm{T} 1$ and to the other half 1 year later. ${ }^{25}$ In the latter group, fewer received the questionnaires, since $9 \%$ could not be sent out because of unknown addresses. To reduce sample attrition because of lacking responses to some of the personality items, scores for a given personality dimension were imputed with mean scores when responses were missing for four or fewer of the nine items (this was the case with 12, 19, 23 and 23 responders in the four different personality dimensions). There were no significant difference in mean scores for the personality dimensions between responders at $\mathrm{T} 1$ and responders 1 year later. As only a few responders had missed the odd item for the other predictor variables (response rates compared with baseline ranging from 514/522; $98.5 \%$ to $520 / 522 ; 99.6 \%$ ), we decided not to impute these variables but removed these cases in our regression analyses. Because the lack of data for the personality variables lowered the response rate with $8 \%$ at T2\% and $5 \%$ at T3, we performed ancillary analyses without the personality variables and found identical significant adjusted predictors at both T2 and T3. Attrition bias tests, comparing responders at $\mathrm{T} 1$ with responders at $\mathrm{T} 2$ and T3, respectively, showed a significant difference between responders and non-responders at $\mathrm{T} 2$, where responders were approximately 1 year younger than non-responders $(\mathrm{p}=0.004)$. There were no significant differences between responders and non-responders at $\mathrm{T} 3$.

\section{Ethics}

The longitudinal NORDOC study has been approved by the Regional Committee for Medical Research Ethics, Southern Norway, Section A: 2009/788a.

\section{RESULTS}

The mean PMCW score at T2 was $22.3(\mathrm{SD}=4.2)$ and increased to $24.5(\mathrm{SD}=3.0)$ at T3 $(\mathrm{t}=8.2, \mathrm{p}<0.001$, Cohen's $d=0.6)$. The scores ranged from 8 to 28 . There were no significant differences between the genders in PMCW scores.

Significant univariate associations with PMCW at T2 were found for: vulnerability, reality weakness, perceived medical school stress, identification with the role of doctor, perceived medical recording skills and the use of alcohol to cope with tension (table 2). Significant adjusted associations were found for: identification with the role of doctor $(\beta=0.16 ; p=0.006 ; 95 \%$ CI 0.05 to $0.28)$, perceived medical recording skills $(\beta=0.13$; $p=0.02$; $95 \%$ CI 0.02 to 0.24 ) and drinking to cope with tension $(\beta=-2.45 ; \mathrm{p}=0.001 ; 95 \%$ CI -3.88 to -1.03$)$; adjusted $R^{2}=0.15$ (table 2). Logistic regression model yielded exactly the same significant associations. Interaction analyses showed no significant interactions between gender and any of the studied independents, which means that the reported effects basically were the same for both male and female doctors. Post hoc tests showed some heteroscedasticity, $\mathrm{p}=0.019$, with Breusch-Pagan test, but no influential outliers at T2. At T2, a significant but rather undramatic curvilinear association between PMSS and PMCW was found (in which scores in the mid-range of the PMSS scale are associated with lower PMCW).

Significant univariate associations with PMCW at T3 were found for: vulnerability, intensity, reality weakness, perceived medical school stress, identification with the role of doctor and perceived medical recording skills (table 3). The only significant adjusted association was found for: perceived medical recording skills $(\beta=0.11$; $\mathrm{p}=0.015$; $95 \%$ CI 0.02 to 0.21 ), adjusted $R^{2}=0.10$ (table 3 ). Logistic regression model yielded the same significant associations. (In addition, a logistic regression model revealed a significant association between drinking to cope and low PMCW at T3.) Entering PMCW measured at T2 as an independent of PMCW at T3 yielded a moderate association $(\beta=0.20 ; p<0.001 ; 95 \%$ CI 0.10 to 0.30$)$, with perceived medical recording skills remaining significant ( $\beta=0.10 ; p=0.04 ; 95 \%$ CI 0.003 to 0.20 ). There were no significant interactions with gender for any of the predictors. Post hoc tests showed significant heteroscedasticity, $\mathrm{p}=0.002$, with Breusch-Pagan test but no curvilinearity nor influential outliers at T3. With Ordinary Least Squares Regression, the heteroscedasticity observed would not contribute to our committing type I errors, but might induce some caution regarding putative zero findings.

\section{DISCUSSION}

Perceived medical recording skills predicted perceived mastery both 10 and 20 years after graduation. In addition, 10 years after graduation, identification with the role of doctor predicted higher perceived mastery, while use of alcohol to cope with tension was associated with lower perceived mastery. We found no statistically significant gender differences in the effects of any of the independents included in the regression analyses.

To our knowledge, this is the first prospective study on PMCW among doctors. As expected, there was a significant 
Table 2 Predictors at T1 of perceived mastery of clinical work at T2. Multiple linear regressions.

\begin{tabular}{|c|c|c|c|c|c|}
\hline & \multirow[t]{2}{*}{ Unadjusted } & \multicolumn{4}{|l|}{ Adjusted } \\
\hline & & Block 1 & Block 2 & Block 3 & Block 4 \\
\hline & $\beta(B)$ & $\beta(B)$ & $\beta(B)$ & $\beta(B)$ & $\beta(B)$ \\
\hline \multicolumn{6}{|l|}{ Demographic factors } \\
\hline Age & $-0.07(-0.11)$ & $-0.09(-0.15)$ & $-0.09(-0.14)$ & $-0.04(-0.07)$ & $-0.03(-0.05)$ \\
\hline Male gender & $-0.06(-0.52)$ & $-0.11(-0.92)$ & $-0.14(-1.12)^{*}$ & $-0.13(-1.02)^{*}$ & $-0.12(-0.94)$ \\
\hline \multicolumn{6}{|l|}{ Personality } \\
\hline Vulnerability & $-0.21(-0.38)^{4 .+x}$ & & $-0.18(-0.32)^{* *}$ & $-0.15(-0.27)^{*}$ & $-0.10(-0.17)$ \\
\hline Control & $0.01(0.02)$ & & $0.03(0.05)$ & $-0.003(-0.005)$ & $-0.03(-0.05)$ \\
\hline Intensity & $0.11(0.18)^{*}$ & & $0.09(0.14)$ & $0.09(0.14)$ & $0.05(0.07)$ \\
\hline Reality weakness & $-0.17(-0.50)^{* *}$ & & $-0.09(-0.27)$ & $-0.09(-0.24)$ & $-0.06(-0.17)$ \\
\hline \multicolumn{6}{|l|}{ Alcohol drinking habits } \\
\hline Hazardous drinking & $0.004(0.05)$ & & & $0.05(0.56)$ & $0.01(0.11)$ \\
\hline Use of alcohol to cope with tension & $-0.19(-2.45)^{*+x}$ & & & $-0.20(-2.46)^{* *}$ & $-0.20(2.45)^{*+}$ \\
\hline \multicolumn{6}{|l|}{ Medical school factors } \\
\hline Perceived medical school stress & $-0.18(-0.11)^{* *}$ & & & & $0.02(0.02)$ \\
\hline Identification with the role of doctor & $0.25(0.23)^{+* t+}$ & & & & $0.17(0.16)^{* *}$ \\
\hline Perceived medical recording skills & $0.22(0.20)^{*+* t}$ & & & & $0.14(0.13)^{*}$ \\
\hline $\mathbf{R}^{2}$ ( $\mathbf{R}^{2}$ change) & & $0.01(0.02)$ & $0.07(0.07)$ & $0.10(0.03)$ & $0.15(0.05)$ \\
\hline
\end{tabular}

${ }^{*} p \leq 0.05,{ }^{* *} p \leq 0.01,{ }^{* * *} p \leq 0.001$

$\beta$, standardised beta; $\mathrm{B}$, unstandardised Beta; $R^{2}$, adjusted $R^{2} ; R^{2}$ change, adjusted $R^{2}$ change.

Table 3 Predictors at T1 of perceived mastery of clinical work at T3. Multiple linear regressions.

\begin{tabular}{lllll} 
Unadjusted & Adjusted & & & \\
\hline & Block 1 & Block 2 & Block 3 & Block 4 \\
\hline$\beta(\mathrm{B})$ & $\beta(\mathrm{B})$ & $\beta(\mathrm{B})$ & $\beta(\mathrm{B})$ & $\beta(\mathrm{B})$ \\
$0.03(0.04)$ & $0.02(0.02)$ & $0.02(0.03)$ & $0.04(0.04)$ & $0.04(0.05)$ \\
$-0.07(0.44)$ & $-0.05(-0.29)$ & $-0.06(-0.34)$ & $-0.06(-0.34)$ & $-0.05(-0.30)$
\end{tabular}

\begin{tabular}{|c|c|c|c|c|c|}
\hline \multicolumn{6}{|l|}{ Demographic factors } \\
\hline Age & $0.03(0.04)$ & $0.02(0.02)$ & $0.02(0.03)$ & $0.04(0.04)$ & $0.04(0.05)$ \\
\hline Male gender & $-0.07(0.44)$ & $-0.05(-0.29)$ & $-0.06(-0.34)$ & $-0.06(-0.34)$ & $-0.05(-0.30)$ \\
\hline \multicolumn{6}{|l|}{ Personality } \\
\hline Vulnerability & $-0.24(-0.30)^{*+t}$ & & $-0.17(-0.20)^{\star}$ & $-0.16(-0.20)$ & $-0.11(-0.13)$ \\
\hline Control & $0.03(0.03)$ & & $0.06(0.08)$ & $0.05(0.07)$ & $0.03(0.04)$ \\
\hline Intensity & $0.21(0.25)^{* *}$ & & $0.16(0.18)^{*}$ & $0.15(0.17)^{*}$ & $0.13(0.15)$ \\
\hline Reality weakness & $-0.21(-0.42)^{* *}$ & & $-0.12(-0.24)$ & $-0.12(-0.24)$ & $-0.09(-0.18)$ \\
\hline \multicolumn{6}{|l|}{ Alcohol drinking habits } \\
\hline Hazardous drinking & $0.02(0.18)$ & & & $0.03(0.27)$ & $-0.001(-0.01)$ \\
\hline Use of alcohol to cope with tension & $-0.07(-0.68)$ & & & $-0.06(-0.55)$ & $-0.06(-0.50)$ \\
\hline \multicolumn{6}{|l|}{ Medical school factors } \\
\hline Perceived medical school stress & $-0.20(-0.10)^{* *}$ & & & & $0.01(0.01)$ \\
\hline Identification with the role of doctor & $0.19(0.13)^{* *}$ & & & & $0.08(0.05)$ \\
\hline Perceived medical recording skills & $0.26(0.17)^{* * *+}$ & & & & $0.18(0.11)^{*}$ \\
\hline $\mathbf{R}^{2}$ ( $\mathbf{R}^{2}$ change) & & $-0.006(0.003)$ & $0.08(0.10)$ & $0.07(0.004)$ & $0.10(0.04)$ \\
\hline
\end{tabular}

${ }^{*} \mathrm{p} \leq 0.05,{ }^{* *} \mathrm{p} \leq 0.01,{ }^{* * *} \mathrm{p} \leq 0.001$.

$\beta$, standardised beta; $\mathrm{B}$, unstandardised beta; $R^{2}$, adjusted $R^{2} ; R^{2}$ change, adjusted $R^{2}$ change. 
increase in perceived mastery over the 10 years, which may be due to more experience and increased competence during 10 years of practice.

Perceived medical recording skills predicted perceived mastery both early in the doctors' careers, when they were in learner/junior positions, and as long as 20 years later, when they were in more senior positions. Recording skills has previously predicted higher job satisfaction 4 years after graduation ${ }^{35}$ and lower job stress in the first postgraduate year, ${ }^{15}$ possibly because junior doctors make many medical records, but to our knowledge, this is the first finding of recording skills being a predictor over 20 years. Recording skills are related to communication skills, namely, skills in taking a history from real patients and writing up a medical record. Former research showed-not very surprisingly-that medical students had lower self-confidence in medical skills that they rarely performed ${ }^{36}$ indicating the importance of practicing in real clinical settings to enhance perceived recording skills and to experience future perceived mastery. One could argue that self-esteem would be associated with both perceived skills and perceived mastery. By controlling for vulnerability, which is highly correlated $(\mathrm{r}=0.7)$ with low self-esteem, ${ }^{37}$ we believe that we have in fact adjusted for this possible confounder.

Identification with the role of doctor predicted perceived mastery 10 years after leaving medical school, when many were not yet in their established positions. Factors shown to promote such role identification are confidence in one's own knowledge, perceived recording skills, not having considered dropping out of medical school and low levels of perceived medical school stress. ${ }^{19}$

Drinking alcohol to cope with tension as a student was associated with lower perceived mastery 10 years after leaving medical school. Life changes and role transitions have been linked to more drinking in other populations, ${ }^{38}$ and we know that young doctors are in stressful positions, being on call and in shift work. This unhealthy coping behaviour seems to have been most important over the early years of their career when more of the doctors were still in a learners' position, presumably having less clinical experience and being exposed to stressful new challenges.

\section{Implications for the medical school curricula}

The most important implication of these findings for medical educators is that work to ensure students' confidence in their recording skills is likely to have life-long effects. Recording skills are about being able to combine biomedical theoretical knowledge and communication skills, and then being able to summarise this in a medical record. In line with this argument, learning styles that promote a combination involving theoretical knowledge in a practical setting are positively associated with academic performance. ${ }^{39}$ Learning in practically demanding settings is especially linked to the development of communication skills, ${ }^{40}$ which can enhance interpersonal awareness during medical school, ${ }^{41}$ as well as future professional competence ${ }^{42}$ and patient satisfaction. ${ }^{43}$ Studies show that courses where students practice in simulated, or preferably in real-world, complex situations can improve medical students' performance. $^{44}{ }^{45}$ It is, however, important that this practice involves immediate, focused feedback, given by experienced teachers. ${ }^{46}$ Such education is expensive, and the development of standardised assessment measures ${ }^{47}$ and reliable self-assessment tools ${ }^{48}$ is needed.

New research shows that so called 'self-reflexivity' can enhance both professional identity development ${ }^{49}$ and integration of theoretical knowledge with professional practice. ${ }^{50}$ Self-reflexivity involves reflecting on one's professional role in the interaction with patients and colleagues, as well as reflecting about the potential influence of contextual factors on both the patient and oneself. This is in line with medical education developing its scope from a pure biomedical focus to a more comprehensive view including communicative practices and patient centredness. ${ }^{51}$ To develop self-reflexivity, it is however essential to get proper feedback, to have good role models among teaching staff and for the students to be in an environment that feels emotionally safe. ${ }^{49}$ Self-reflexivity could help the students to develop more active and problem-focused ways of coping when facing challenges, instead of using avoidance strategies like drinking alcohol to cope with stress and tension.

\section{Implications for future research}

Apart from the need for more studies on predictors of perceived medical recording skills, more studies and evaluations are required on the effects of medical school interventions and training courses that improve both role identification and medical recording skills. ${ }^{52} 53$ Perceived mastery is seldom studied, at least in the medical profession, and it should be validated with respect to observed performance. There is also a need for more studies on what characterises different trends in perceived mastery over time, such as an increase or decline in this perception and their association with contextual factors, coping strategies and mental health.

\section{Strengths and limitations}

This 20-year prospective design, with a nationwide representative sample of Norwegian doctors, is unique. The response rates were relatively high for such a long-term follow-up, and the differences between responders and non-responders were small (non-responders at T2 were approximately 1 year older than responders).

Limitations include the use of self-reported measures of skills and mastery, because previous studies have found that these are often poorly correlated with observed skills, ${ }^{54}$ and contextual factors, such as specialty, practice venues and other work-related factors, might be of importance for observed clinical performance among the doctors. By controlling for vulnerability, which resembles neuroticism, self-criticism and low self-esteem, we have adjusted for underestimating one's own skills. We have not sufficiently controlled for overestimation of 
own skills and mastery, since the study does not include any measurement that can be argued to measure risk of overestimation. Moreover, the Cronbach's $\alpha$ values for the four personality scales are very low (between 0.62 and 0.77 ), which in multivariate analyses could increase the risk of false-positive results, type I errors. Since more than 20 years have passed since the onset of this study, issues such as problematic alcohol behaviour may have been superseded by factors such as problematic use of drugs. The total explained variance was $15 \%$ at T2\% and $10 \%$ at T3, which emphasises that contextual factors such as specialty and positions might be of importance.

\section{CONCLUSIONS}

Our study indicates that students who leave medical school with a high degree of physician role identification and confidence in their own skills are likely to perceive higher mastery of their clinical work as long as 20 years after graduation. Drinking alcohol to cope with tension is however a risk factor of lower future perceived mastery, which indicates the importance of learning healthy strategies to cope with stress already in medical school.

Contributors All authors had full access to all the data in the study and take responsibility for the integrity of the data and the accuracy of the data analysis. The lead author affirms that this manuscript is an honest, accurate, and transparent account of the study being reported; that no important aspects of the study have been omitted; and that any discrepancies from the study as planned have been explained. Study concept and design: AB, RT. Acquisition, analysis, or interpretation of data: All authors. Drafting of the manuscript: All authors. Critical revision of the manuscript for important intellectual content: All authors. Statistical analysis: AB, RT, TM. Obtained funding: RT, LL. Administrative, technical, or material support: LL. Study supervision: RT, LL, KSG.

Funding The study was funded by the Norwegian National Advisory Unit on Concurrent Substance Abuse and Mental Health Disorders, Innlandet Hospital Trust, Norway. The Longitudinal NORDOC study has been founded by the Norwegian Research Council, the Norwegian Medical Association and the University of Oslo, Norway.

Competing interests None declared.

Ethics approval Regional Committee for Medical Research Ethics, Southern Norway, Section A: 2009/788a.

Provenance and peer review Not commissioned; externally peer reviewed. Data sharing statement № additional data available.

Open Access This is an Open Access article distributed in accordance with the Creative Commons Attribution Non Commercial (CC BY-NC 4.0) license, which permits others to distribute, remix, adapt, build upon this work non-commercially, and license their derivative works on different terms, provided the original work is properly cited and the use is non-commercial. See: http://creativecommons.org/ licenses/by-nc/4.0/

(C) Article author(s) (or their employer(s) unless otherwise stated in the text of the article) 2017. All rights reserved. No commercial use is permitted unless otherwise expressly granted.

\section{REFERENCES}

1. van Praag HM. Can stress cause depression? Prog Neuropsychopharmacol Biol Psychiatry 2004;28:891-907.

2. Hertzberg TK, Rø KI, Vaglum PJ, Hertzberg Kolstad T, Isaksson $\mathrm{R} ø \mathrm{~K}$, et al. Work-home interface stress: an important predictor of emotional exhaustion 15 years into a medical career. Ind Health 2016;54:139-48.
3. Shanafelt TD, Bradley KA, Wipf JE, et al. Burnout and self-reported patient care in an internal medicine residency program. Ann Intern Med 2002;136:358-67.

4. Fahrenkopf AM, Sectish TC, Barger LK, et al. Rates of medication errors among depressed and burnt out residents: prospective cohort study. BMJ 2008;336:488-91.

5. Pruessner JC, Baldwin M. Biological aspects of self-esteem and stress. In: Gendolla GHE, Mattie T, Sander LK, eds. Handbook of Biobehavioral Approaches to Self-Regulation. New York: Springer, 2015:385-95

6. Ursin H, Olff M. Psychobiology of coping and defence strategies. Neuropsychobiology 1993;28:66-71.

7. Siltaloppi M, Kinnunen U, Feldt T. Recovery experiences as moderators between psychosocial work characteristics and occupational well-being. Work Stress 2009;23:330-48.

8. Knardahl S, Work Mof. In: Lindström K, ed. Review of Psychological and Social Factors at Work and Suggestions for the General Nordic Questionnaire (QPSNordic). Copenhagen: Nordic Council of Ministers 1997:63-6.

9. Bandura A. Self-efficacy: The Exercise of Control. New York: W.H. Freeman and Company 1997:79-86.

10. Theorell T, Karasek RA. Current issues relating to psychosocial job strain and cardiovascular disease research. J Occup Health Psychol 1996;1:9-26.

11. Karasek RA. Theorell T. Healthy work: Stress, productivity, and the reconstruction of working life. New York: Basic Books, 1990.

12. Bradley GL. Work-induced changes in feelings of mastery. J Psychol 2010;144:97-119.

13. Dyrbye LN, Thomas MR, Shanafelt TDSystematic Review of Depression, Anxiety and Other Indicators of Psychological Distress among U.S. and Canadian Medical Students. Acad Med 2006;81:354-73.

14. Gulbrandsen $P$, Jensen BF, Finset $A$, et al. Long-term effect of communication training on the relationship between physicians' selfefficacy and performance. Patient Educ Couns 2013;91:180-5.

15. Tyssen R, Vaglum P, Grønvold NT, et al. The relative importance of individual and organizational factors for the prevention of job stress during internship: a nationwide and prospective study. Med Teach 2005;27:726-31.

16. Byszewski A, Hendelman W, McGuinty C, et al. Wanted: role models-medical students' perceptions of professionalism. BMC Med Educ 2012;12:115

17. Hendelman W, Byszewski A. Formation of medical student professional identity: categorizing lapses of professionalism, and the learning environment. BMC Med Educ 2014;14:139.

18. Skogstad A. Role expectations. Lindström K, ed. Review of Psychological and Social Factors at Work and Suggestions for the General Nordic Questionnaire (QPSNordic. . Copenhagen: Nordic Council of Ministers, 1997:1997. 47-50.

19. Gude T, Vaglum P, Tyssen R, et al. Identification with the role of doctor at the end of medical school: a nationwide longitudinal study. Med Educ 2005;39:66-74.

20. Ljoså $\mathrm{CH}$, Tyssen R, Lau B. Perceived mastery of work among shift workers in the Norwegian offshore petroleum industry. Ind Health 2013;51:145-53.

21. Berg AM, Hem E, Lau B, et al. Stress in the Norwegian police service. Occup Med 2005;55:971-82.

22. Oreskovich MR, Shanafelt T, Dyrbye LN, et al. The prevalence of substance use disorders in American physicians. Am J Addict 2015;24:30-8.

23. Tyssen R, Vaglum P, Aasland OG, et al. Use of alcohol to cope with tension, and its relation to gender, years in medical school and hazardous drinking: a study of two nation-wide Norwegian samples of medical students. Addiction 1998;93:1341-9.

24. Mahmood JI, Grotmol KS, Tesli M, et al. Risk Factors Measured During Medical School for Later Hazardous Drinking: A 10-year, Longitudinal, Nationwide Study (NORDOC). Alcohol Alcohol 2016;51:71-6.

25. Tyssen R, Vaglum P, Gronvold NT, et al. The impact of job stress and working conditions on mental health problems among junior house officers. A nationwide Norwegian prospective cohort study. Med Educ 2000;34:374-84.

26. Lazare A, Klerman GL, Armor DJ, Oral ADJ. Oral, obsessive, and hysterical personality patterns. An investigation of psychoanalytic concepts by means of factor analysis. Arch Gen Psychiatry 1966;14:624-30.

27. Torgersen S. The oral, obsessive, and hysterical personality syndromes. A study of hereditary and environmental factors by means of the twin method. Arch Gen Psychiatry 1980;37:1272-7.

28. Torgersen S, Alnæs R. Localizing DSM-III Personality Disorders in a Three-Dimensional Structural Space. J Pers Disord 1989;3:274-81. 
29. Vitaliano PP, Russo J, Carr JE, et al. Medical school pressures and their relationship to anxiety. J Nerv Ment Dis 1984;172:730-6.

30. Bramness JG, Fixdal TC, Vaglum P. Effect of medical school stress on the mental health of medical students in early and late clinical curriculum. Acta Psychiatr Scand 1991;84:340-5.

31. Tyssen R, Vaglum P, Grønvold NT, et al. Factors in medical school that predict postgraduate mental health problems in need of treatment. A nationwide and longitudinal study. Med Educ $2001 ; 35: 110-20$.

32. Midtgaard M, Ekeberg $\varnothing$, Vaglum P, et al. Mental health treatment needs for medical students: a national longitudinal study. Eur Psychiatry 2008;23:505-11.

33. Holm M, Tyssen R, Stordal KI, et al. Self-development groups reduce medical school stress: a controlled intervention study. BMC Med Educ 2010;10:23.

34. Timmer SG, Veroff J, Colten ME, et al; helplessness, and the use of alcohol and drugs to cope: An analysis of national survey data. In: Schiffman S, Wills TA, eds. Coping and substance use. New York: Academic Press, 1985:171-98.

35. Finset KB, Gude T, Hem E, et al. Which young physicians are satisfied with their work? A prospective nationwide study in Norway. BMC Med Educ 2005;5:19.

36. Wu EH, Elnicki DM, Alper EJ, et al. Procedural and interpretive skills of medical students: experiences and attitudes of third-year students. Acad Med 2006;81:48-51.

37. Tyssen R. Medical health problems among medical students and young physicians: a nationwide and longitudinal study [thesis]. Oslo: University of Oslo, 2001

38. Roman PM, Blum TC, transitions L. work and alcohol: An overview and preliminary data. Alcohol Clin Exp Res 1992;16:149-58.

39. Ferguson E, James D, Madeley L. Factors associated with success in medical school: systematic review of the literature. BMJ 2002;324:952-7.

40. Jorm C, Roberts C, Lim R, et al. A large-scale mass casualty simulation to develop the non-technical skills medical students require for collaborative teamwork. BMC Med Educ 2016;16:83.

41. Yedidia MJ, Gillespie CC, Kachur E, et al. Effect of communications training on medical student performance. JAMA 2003;290:1157-65.

42. Epstein RM, Hundert EM. Defining and assessing professional competence. JAMA 2002;287:226-35.
43. Boissy A, Windover AK, Bokar D, et al. Communication Skills Training for Physicians Improves Patient Satisfaction. J Gen Intern Med 2016;31:755-61.

44. Higgins MF, Macken AP, Coyle O, et al. How to teach practical skills in medicine: out of hospital training. Ir Med $J$ 2013;106:17-18.

45. O'Gorman CS, Macken AP, Coyle O, et al. How to teach practical skills in medicine: bridging the gap from the course to the patient, and teaching on the job. Ir Med J 2013;106:18-19.

46. Gotterer GS, Petrusa E, Gabbe SG, et al. A program to enhance competence in clinical transaction skills. Acad Med 2009;84:838-43.

47. Sigalet E, Donnon T, Cheng A, et al. Development of a team performance scale to assess undergraduate health professionals. Acad Med 2013;88:989-96

48. Gordon CJ, Jorm C, Shulruf B, et al. Development of a selfassessment teamwork tool for use by medical and nursing students. BMC Med Educ 2016;16:218.

49. Luft T, Roughley R. et a/Engaging the Reflexive Self: The role of Reflective Practice for Supporting Professional Identity Development in Graduate Students. In: Flores KA, Kirstein KD, Schieber CE, Olswang SG, ; eds. Supporting the Success of Adult and Online Students: Proven Practices in Higher Education. CreateSpace Independent Publishing Platform, 2016:53-62.

50. Bolton G. Reflective practice: Writing and professional development. 4th ed. London: Sage Publications, 2014

51. Wiese V. Skolens Janusansikt: Utskilling eller utvikling i ulike læringsmiljø [thesis. Gjovik: Norwegian University of Science and Technology, 2007.

52. de Lasson L, Just E, Stegeager N, et al. Professional identity formation in the transition from medical school to working life: a qualitative study of group-coaching courses for junior doctors. BMC Med Educ 2016;16:165.

53. Cruess RL, Cruess SR, Boudreau JD, et al. Reframing medical education to support professional identity formation. Acad Med 2014;89:1446-51.

54. Pena G, Altree M, Field J, et al. Surgeons' and trainees' perceived self-efficacy in operating theatre non-technical skills. Br J Surg 2015;102:708-15. 